\title{
Mycobacteriosis in patients with breast implants: a case review from the Ivo Pitanguy Institute
}

\author{
Micobacteriose em implantes mamários: revisão da casuística do Instituto Ivo
} Pitanguy

\author{
Gabrielle Bessa Wajnberg ${ }^{1}$ \\ Vinicius Volpe D'AngIerI \\ BASILE $^{2}$ \\ Luís Gustavo Moraes \\ PRADO ${ }^{2}$ \\ José DE FARIA ${ }^{3}$ \\ Henrique N. Radwanski ${ }^{3}$ \\ Ivo PitanguY ${ }^{4}$
}

Study conducted at the Plastic Surgery Service of Professor Ivo Pitanguy, Santa Casa da Misericórdia do Rio de Janeiro, Rio de Janeiro, RJ, Brazil.

Submitted to SGP (Sistema de Gestão de Publicações/Manager Publications System) of RBCP (Revista Brasileira de Cirurgia

Plástica/Brazilian Journal of Plastic Surgery).

Received: July 18, 2011 Accepted: August 30, 2011

\begin{abstract}
Introduction: Reports of infections caused by rapidly growing mycobacteria during plastic surgery have increased in recent years despite improvements in techniques of asepsis/ antisepsis and antibiotic prophylaxis. Infections occurring after the insertion of breast implants are a cause of patient morbidity and a significant problem for the surgeon. Methods: Breast implant surgery cases complicated by mycobacterial infections at the Infirmary ward $38^{\text {th }}$ of the Santa Casa da Misericórdia, Rio de Janeiro were retrospectively reviewed. A description of the current guidelines for the prevention and treatment of mycobacteriosis is included. Laboratory confirmed and clinically suspected cases were included in this study. Results: Of 483 augmentation mammaplasty cases, 3 patients developed mycobacterial infections in the last 3 years. In 2 patients, there was a suspicion of infection that was not confirmed by laboratory data. Conclusions: Prophylaxis is fundamental for reducing the incidence of mycobacteriosis during plastic surgery procedures. However, the identification, diagnosis, and treatment of mycobacterial diseases are important to minimize the morbidity of this type of infection.
\end{abstract}

Keywords: Mycobacteria, atypical. Mycobacterium. Breast implantation. Mammaplasty/ adverse effects. Infection.

\section{RESUMO}

Introdução: Nos últimos anos, foram crescentes os registros de infecções por micobactéria de crescimento rápido em cirurgia plástica, mesmo com a melhoria dos métodos de assepsia/ antissepsia e da antibioticoprofilaxia. A infecção após inclusão de implantes mamários causa grande morbidade às pacientes e transtorno ao cirurgião. Método: Estudo retrospectivo dos casos de infecção por micobactéria de crescimento rápido da $38^{\mathrm{a}}$ Enfermaria da Santa Casa da Misericórdia do Rio de Janeiro, após inclusão de implantes mamários, em que são apresentadas propostas de prevenção e tratamento da micobacteriose. Foram incluídos os casos confirmados laboratorialmente e os clinicamente suspeitos. Resultados: Até o presente momento foram confirmados 3 casos de infecção por micobactéria, num total de 483 mamaplastia de aumento no decorrer de 3 anos. Em 2 pacientes, houve suspeita de infecção, porém sem confirmação laboratorial. Conclusões: A profilaxia é o pilar fundamental para a redução do impacto da micobacteriose em procedimentos de cirurgia plástica. Entretanto, saber identificar, diagnosticar e tratar corretamente a micobacteriose é de suma importância para minimizar a morbidade da paciente.

Descritores: Micobactérias atípicas. Mycobacterium. Implante mamário. Mamoplastia/efeitos adversos. Infecção.

1. Plastic Surgeon, Postgraduate at Instituto Ivo Pitanguy, Rio de Janeiro, RJ, Brazil.

2. General Surgeon, Postgraduate Student at Instituto Ivo Pitanguy, Rio de Janeiro, RJ, Brazil.

3. Plastic Surgeon, Full Member of the Brazilian Society for Plastic Surgery (BSPS), Assistant Professor of the Postgraduate Medical School In Plastic Surgery at Pontifícia Universidade Católica do Rio de Janeiro (PUC-RJ) and at Instituto de Pós-Graduação Médica Carlos Chagas, Rio de Janeiro, RJ, Brazil.

4. Patron of BSPS, Member of the Academia Nacional de Medicina e Academia Brasileira de Letras, Full Professor of the Medical Postgraduate School of Plastic Surgery at PUC-RJ and at Instituto de Pós-Graduação Médica Carlos Chagas, Rio de Janeiro, RJ, Brazil. 


\section{INTRODUCTION}

Infection is one of the most feared complications of breast implant surgery, occurring in $1 \%$ to $2 \%$ of surgery cases ${ }^{1}$. The most common causative agents are Staphylococcus aureus and coagulase-negative Staphylococcus. Although uncommon, postoperative infection in breast implant surgery is associated with significant morbidity. In most cases, these patients require additional operations and prolonged antibiotic treatment, which may compromise the result of the original surgery. In addition to implant removal, implant re-insertion surgery can be delayed for months or even years ${ }^{2}$.

Reports of mycobacterial infections after cosmetic surgery have been increasing in recent years, particularly those in association with liposuction and augmentation mastoplasty ${ }^{3}$. This may be due to the contamination of surgical instruments, immunosuppression of the host, or establishment of new laboratory methods of diagnosis 2 .

Mycobacteria, which are abundant in the environment, were first described by Hansen in $1868^{3}$. These organisms have peculiarities related to the amount and types of complex lipids in their cell walls. This unique cell wall, rich in lipids, is an efficient and impermeable barrier, and it increases the antibiotic resistance of mycobacteria in comparison to other bacteria.

The rapidly growing mycobacteria Mycobacterium fortuitum, M. chelonae, and M. abscessus are opportunistic microorganisms, normally found in soil, dust, and water pipes. They rarely cause diseases in humans, unless they are inoculated directly into the body through wounds or contaminated surgical equipment.

The largest group of atypical mycobacteria of clinical importance, according to the classification of Runyon, is the group of fast-growing bacteria or group 4. Often involved in skin and soft tissue infections, they have been associated with infections caused by intravenous and peritoneal catheters, abscesses after injections, surgical site infections, mastoplasties, and ophthalmic surgeries ${ }^{3}$.

Mycobacterial infections can have a presentation similar to that of other microbial agents commonly associated with implant surgery, except that they are characterized by a later onset, approximately 4 to 6 weeks after surgery. The clinical presentation of mycobacterial infection includes an odorless and colorless secretion in the surgical wound, and it may be accompanied by systemic signs such as fever and asthenia.

The diagnosis of mycobacterial disease requires a positive culture for this organism. Aspirated material should be Gram stained; tested for acid-alcohol resistant bacillus (BAAR); and cultured for aerobic and anaerobic bacteria, fungi, and mycobacteria ${ }^{4}$. The determination of the mycobacterial subtype is extremely important to determine the specific antibiotic therapy. To this end, 2 biochemical tests are commonly used: tolerance to sodium chloride and to citrate, and the polymerase chain reaction (PCR).

The present study is an analysis of the prognosis and treatment of mycobacterial infection based on a review of the incidence, diagnostic methods, progression, and treatment of mycobacterial infection patients in the Ivo Pitanguy Plastic Surgery Institute at Infirmary ward 38 of the Santa Casa da Misericordia, Rio de Janeiro.

\section{METHODS}

The medical records of patients who developed infections caused by rapidly growing mycobacteria after breast implant surgery were reviewed. Only infections confirmed by laboratory data during 2008, 2009, and 2010 were included. Two cases of suspected infection without laboratory confirmation that were treated for mycobacteriosis were also reviewed.

This study was approved by the Ethics Committee of the Ivo Pitanguy Plastic Surgery Institute.

\section{RESULTS}

\section{Reports of Confirmed Cases}

First case - A 23-year-old woman underwent surgery for the insertion of round silicone breast implants with polyurethane coating, $285 \mathrm{ml}$ in the right and $195 \mathrm{ml}$ in the left breast through a lower periareolar incision at the retroglandular location on March 3, 2008. On the $22^{\text {nd }}$ day after surgery, the patient complained of weight in the right breast, without local and/or systemic signs of inflammation. An ultrasonongaphy was obtained, and it evidenced an infected fluid collection. On postoperative day 36 , a spontaneous serous drainage was detected at the right breast incision site, and the drainage was sent for culture and sensitivity tests. Antibiotic therapy with ciprofloxacin (500 mg every 12 hours) was started.

The culture was positive for $M$. abscessus. The breast implants were removed, and the patient was referred to an infectious diseases specialist. After the removal of the implants, the patient did not comply with the follow-up recommendations.

Second case - A 31-year-old woman underwent silicone breast implant surgery, with round, textured, 260-ml implants inserted through a lower periareolar incision at the retroglandular location on February 4, 2009. On day 15 day after surgery, there was a purulent discharge from the right breast incision site. The cultures of the discharge were sent for analysis, and the patient was treated with ciprofloxacin (500 mg every 12 hours for 15 days). The culture results were negative for bacteria. Because the clinical condition remained unchanged, the breast implants were removed on day 30 and the material, including a fragment of tissue from the infected region, was resent for culturing. 
The culture result was again negative for mycobacterial disease, but the tissue sample analyzed showed alterations consistent with infection by rapidly growing mycobacteria: chronic granulomatous inflammatory process and necrotizing granulomas with the presence of epithelioid cells, histiocytes, and giant cells (Figure 1).

The patient was treated for rapidly growing mycobacteria with clarithromycin (500 mg orally every 12 hours for 4 months). On August 4, 2009, breast implant surgery was performed again using a similar size and shape of implant and the same surgical scars at the retroglandular position, with no reported complications to date.

Third case - A 34-year-old woman underwent insertion of round, textured, $305-\mathrm{ml}$ silicone breast implants through a lower periareolar incision at the retroglandular location on July 15, 2010. On day 13 after surgery, she presented with hematoma in both breasts. Drainage of the hematoma was performed in the operating room, and after irrigation of the undermined areas, the implants were re-inserted through the same incision. Drainage tubes were left in place for 2 days. The patient was maintained on antibiotic therapy with ciprofloxacin $(500 \mathrm{mg}$ every 12 hours) for 15 days.

On day 28 after surgery, the patient presented with an increased volume of the right breast and asthenia. The ultrasonography revealed fluid collection posterior to the implant in the right breast, and the blood count was normal. The material was aspirated with a Klein needle and sent for culture and sensitivity tests (Figure 2). The patient was hospitalized with fever and signs of inflammation around the area of puncture, and was started on intravenous antibiotic therapy. As there was no improvement in her clinical condition, her breast implants were removed and culture of the collected material was requested.

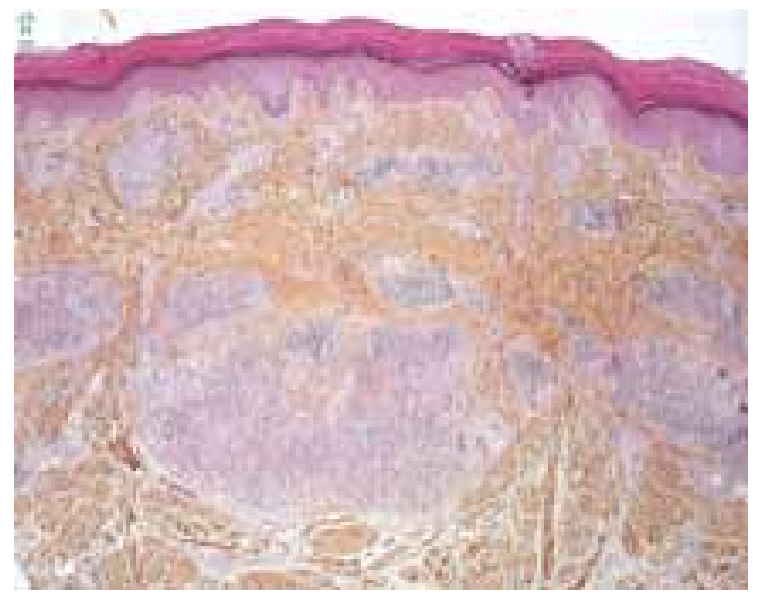

Figure 1-Micrograph of cutaneous granuloma caused by mycobacteriosis.
The patient recovered well in the first 48 hours of ciprofloxacin use. Three days later, there was a positive result for BAAR in all samples and clarithromycin $500 \mathrm{mg}$ was given every 12 hours orally. After 3 weeks, samples tested positive for mycobacterial disease. The patient was kept on oral antibiotics with ciprofloxacin and clarithromycin, awaiting the completion of the antibiotic therapy for re-insertion of new implants.

\section{Reports of Suspected Cases}

First case - A 23-year-old woman underwent surgery for insertion of round, textured, $325-\mathrm{ml}$ silicone breast implants through a lower periareolar incision at the retroglandular location on September 1, 2009. On postoperative day 60, the patient presented with a purulent discharge at the scar. The patient was treated with ciprofloxacin (500 mg every 12 hours for 10 days), and a dry dressing was applied to the wound.

After 9 days, the patient presented with partial exposure of the right breast implant, requiring removal of the implant; cultures were obtained for anatomopathological examination of the tissue sample. All tests gave negative results for mycobacterial disease. Considering the clinical condition compatible with this disease, the patient was placed on antibiotic therapy with ciprofloxacin and clarithromycin for 6 months. On April 16, 2010, the implants were reinserted without complications.

Second case - A 24-year-old woman underwent insertion of round, textured, 235-ml silicone breast implants through a lower periareolar incision at the retroglandular location on May 24, 2007. After 15 months, the patient underwent removal of the right breast implant due to seroma. During surgery, no sign of infection was detected. Tissue samples
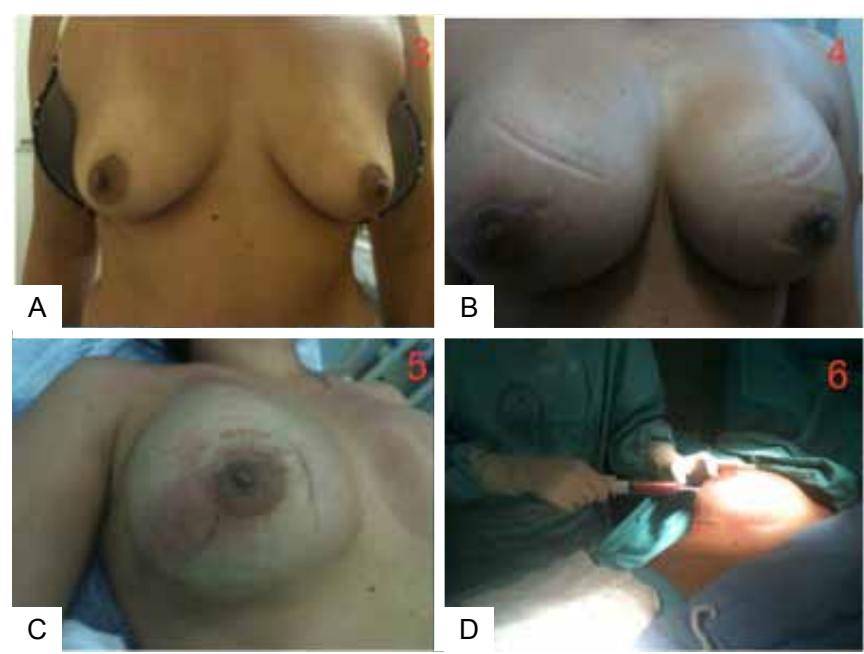

Figure 2-A: Preoperative. B: Volume enlargement of the right breast. C: Area of hyperemia of the right breast. D, Right breast secretion. 
were sent for culturing and anatomopathological examination, and a new implant was inserted. All tests were negative for mycobacteria.

After 6 months, the patient was hospitalized for removal of both implants because they were partially exposed. The cultures again tested negative for mycobacteria. Due to the clinical condition compatible with mycobacterial disease, the patient was placed on antibiotic therapy with ciprofloxacin and clarithromycin for 6 months. On November 3, 2009, the implants were reinserted.

\section{DISCUSSION}

The initial treatment for infection involving breast implants includes empirical antimicrobial therapy ${ }^{2,}{ }^{3}$. If antibiotic treatment is not effective, the presence of infection at the implant area is suspected, and our recommendation is to remove the implant with debridement of the undermined spaces and placement of drains. If the condition of the patient improves after the removal of the implants and antibiotic therapy, the treatment should be continued until the cultures test negative for mycobacteria. However, if the patient does not show improvement in the systemic signs or if the symptoms worsen, mycobacterial infection should be suspected and intravenous therapy with amikacin and cephalothin in standard doses should be administered. The microbial sensitivity test results may be used for dose adjustment ${ }^{2}$.

Antimicrobial therapy with 2 different types of antibiotics during a period of 3 to 6 months, together with implant removal and debridement of the granulation tissue is the recommended treatment strategy. Capsulectomy for the total eradication of mycobacterial disease is imperative. Mycobacteria form biofilms in these implants, making their removal very difficult. Reinsertion of the implants should not be attempted before a 6-month antibiotics course is completed ${ }^{2}$.

In mild to moderate infections, which occur in majority of the cases, treatment can be carried out with oral administration of clarithromycin and ciprofloxacin, trimethoprimsulfamethoxazole, or tetracycline.

For the treatment of M. fortuitum, clarithromycin (500 $\mathrm{mg}$ twice per day, orally), and ciprofloxacin (500 mg twice per day, orally) should be administered in combination for a period of 4 to 6 months. Other possible drugs include amikacin, sulfonamides, imipenem, doxycycline, and cefoxitin.

For the treatment of $M$. abscessus and M. chelonae infections, which are characterized by extensive cutaneous or non-responsive forms, clarithromycin $(500 \mathrm{mg}$ twice per day, orally or $1,000 \mathrm{mg}$ twice per day) should be administered for 4 to 6 months, and amikacin $(250 \mathrm{mg}$ thrice per week for 90 days or $750 \mathrm{mg}$ thrice per week, intramuscularly or intravenously) should be administered for 30 days.

An exacerbation of the symptoms may be observed during treatment in association with an intense immune response, which shows clinical symptoms similar to those caused by the infectious agent but with increased intensity. In such cases, treatment should be extended for 12 months and a sensitivity test should be performed to guide therapy and optimize drug combinations $^{4}$ (Figure 3).

The increasing incidence of mycobacterial infections in recent years, especially in minimally invasive procedures like plastic surgery, indicate that the plastic surgeon should remain informed and very alert to this disease.

Mycobacteriosis has a mild presentation in most cases, but carries very deleterious consequences. Mycobacteriosis is associated with a wide variety of organisms, and certain strains have stood out for their virulence, such as M. massiliense. However, there is no common treatment for all the representatives of this group, and this can complicate and delay the correct treatment in many cases.

The spread of the infection is restricted by the formation of a biofilm, which compromises the aesthetic results of surgery, as it may require capsulectomy and removal of implants.

Plastic surgery may benefit from genetic research to provide information on the types of mycobacteria and the virulence of specific strains; this would help reveal the susceptibility of each strain to specific antibiotic therapies. This may also facilitate the development of preventive measures such as the identification of appropriate sterilizing agents for the safe elimination of these organisms from the surgical environment.

Genetic research may enable the development of drugs to prevent the synthesis and/or release of quorum sensing, which is crucial for the formation of biofilms and guarantees an infection with difficult eradication, or even the development of vaccines against the proteins involved in biofilm formation and drugs that act directly on its elimination.

This never before seen increase in the incidence of mycobacteriosis in plastic surgery services worldwide leads us to believe that diseases are evolving together with the best surgical techniques and antisepsis. Thus, the search for more effective methods to prevent infection is active, and it involves many medical resources that are necessary to fight these organisms capable of evolution and growth through mutation, as seen in the case of recent outbreaks of mycobacteriosis.

Infections caused by rapidly growing mycobacteria are related to failures in the cleaning, disinfection, and 


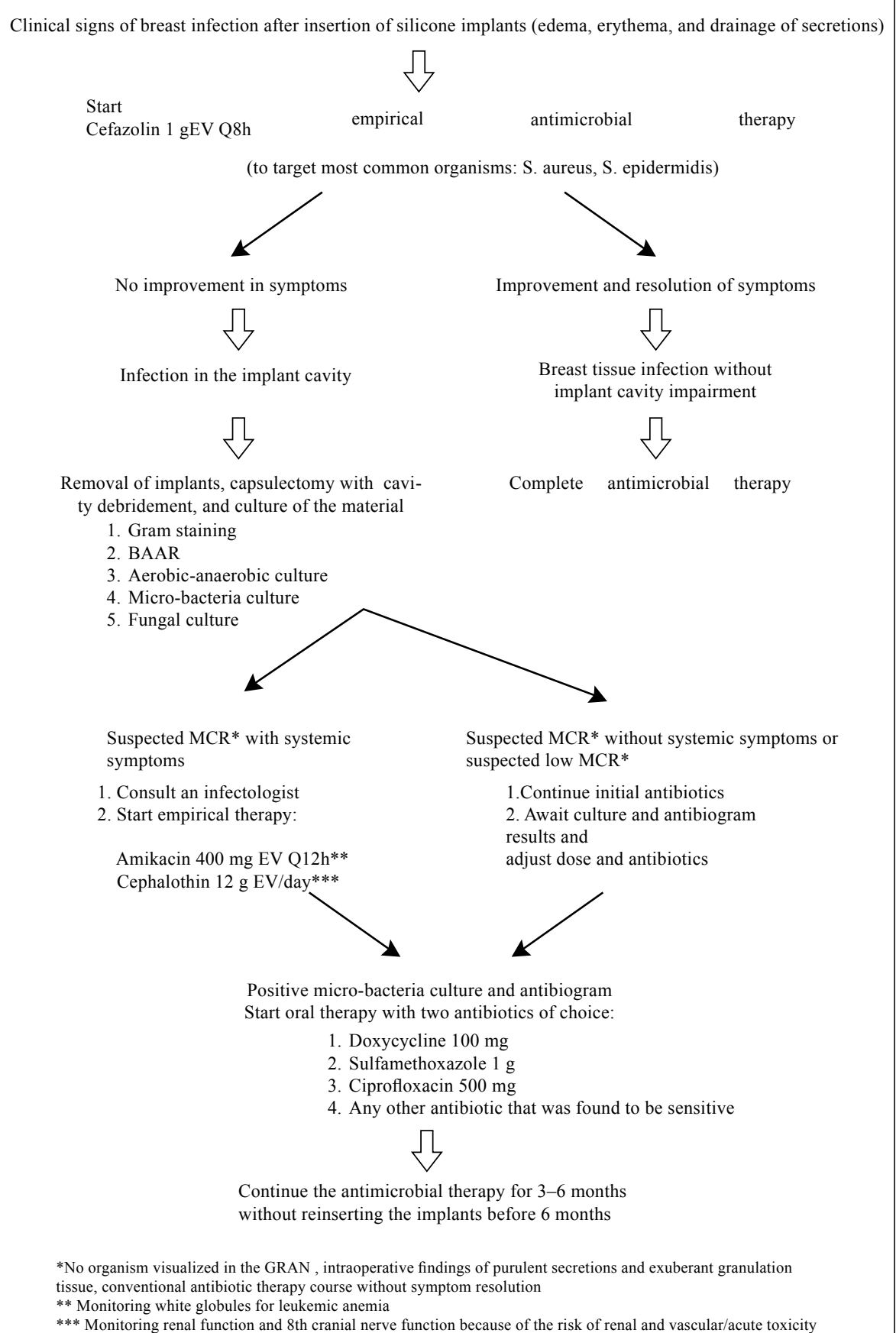

Figure 3-Therapeutic algorithm.

sterilization process of medical products ${ }^{5-9}$. In most of the health services investigated, the surgical instruments were subjected only to the disinfection process and not to the sterilization process, as defined by the Resolution of the National Health Surveillance Agency (ANVISA) - RE $\mathrm{n}^{\mathrm{o}}$ 2606/06. Evidence of the resistance of $M$. massiliense strain to $2 \%$ glutaraldehyde, which until recently was widely used by many health services as a disinfecting agent for surgical instruments, led ANVISA to issue a resolution on August 8, 2008 that mandates the sterilization of critical surgical equipment with other available methods.

In the cases diagnosed in the Infirmary ward 38 of the Santa Casa da Misericordia do Rio de Janeiro, prompt diagnosis and initiation of appropriate treatment for 
mycobacteriosis resulted in the successful detection and eradication of the infection, enabling the insertion of new implants. The sporadic occurrence and lack of outbreaks of this disease at our institute is probably due to the fact that we have followed the recommendations of the competent authorities with regard to proper handling and sterilization of surgical instruments, which were implemented in this service before the occurrence of outbreaks were reported in Brazil.

\section{CONCLUSIONS}

As in the other areas of medicine, prophylaxis is essential for reducing the effect of mycobacterial infections associated with plastic surgery procedures. Following the mandates of the competent auhorities ${ }^{10}$ responsible for proper handling and sterilization of surgical instruments, and adherence to rigorous methods of antisepsis in the preoperative period are the best methods for the prevention of this infection.

However, knowing how to identify and properly treat mycobacterial disease is critical to solve each individual case and to find the infectious source, while optimization of treatment regimens is essential to control infection and reduce morbidity.

\section{REFERENCES}

1. Haiavy $\mathbf{J}$, Tobin H. Mycobacterium fortuitum infection in prosthetic breast implants. Plast Reconstr Surg. 2002;109(6):2124-8.

2. Macadam SA, Mehling BM, Fanning A, Dufton JA, KowalewskaGrochowska KT, Lennox P, et al. Nontuberculous mycobacterial breast implant infections. Plast Reconstr Surg. 2007;119(1):337-44.

3. Macedo JLS, Henriques CMP. Infecções pós-operatórias por micobactérias de crescimento rápido no Brasil. Rev Bras Cir Plást. 2009;24(4):544-51.

4. Secretaria de Estado da Saúde de São Paulo. Centro de Vigilância Epidemiológica "Prof. Alexandre Vranjac". Orientações para investigação clínica e tratamento de infecções por Mycobacterium spp em procedimentos estéticos. Disponívelnem: http://www.cve.saude.sp.gov.br

5. Brickman M, Parsa AA, Parsa FD. Mycobacterium chelonae infection after breast augmentation. Aesthetic Plast Surg. 2005;29(2):116-8.

6. Douglas SR, Cook T, Shorr N. Lumps and bumps: late postsurgical inflammatory and infectious lesions. Plast Reconstr Surg. 2003;112(7):1923-8

7. Kalita JB, Rahman H, Baruah KC. Delayed post-operative wound infections due to non-tuberculous Mycobacterium. Indian J Med Res. 2005;122(6):535-9.

8. Nadell CD, Xavier JB, Levin SA, Foster KR. The evolution of quorum sensing in bacterial biofilms. PLoS Biol. 2008;6(1):e14.

9. Timpe A, Runyon EH. The relationship of atypical acid-fast bacteria to human disease: preliminary report. J Lab Clin Med. 1954;44(2):202-9.

10. Brasil. Agência Nacional de Vigilância Sanitária. RE $n^{\circ} 75$, de 23 de outubro de 2008, que dispõe sobre a comprovação de eficácia de esterilizantes e desinfetantes hospitalares para artigos semi-críticos frente às micobactérias "Mycobacterium abscessus" e "Mycobacterium massiliense" e dá outras providências. Disponível em: http://www.anvisa. gov.br/e-legis/

Correspondence to:

Vinícius Volpe D'Angieri Basile

Av. General San Martin, 856 - ap. 302 - Rio de Janeiro, RJ, Brazil - CEP 22441-014

E-mail: vimedbasile@hotmail.com 